\title{
Diálogo interreligioso por una cultura de paz
}

\author{
Francisco de Aquino Júnior**, \\ Facultad Católica de Fortaleza
}

Este artículo versa sobre el tema tratado en uno de los círculos de debate del II Simposio Brasileño de Cultura, promovido por la Conferencia Nacional de Obispos del Brasil (CNBB) en la Facultad Católica de Fortaleza, los días 17 a 19 de mayo de 2011: "Diálogo interreligioso por una cultura de paz". Lo que ahora pretendemos es solamente problematizar el tema sugerido, aunque, al hacerlo, pongamos las bases para un desarrollo sistemático y profundizado del mismo, tanto por lo que respecta a los fundamentos de la discusión como al modo o al método adecuado de su desarrollo.

El tema, tal como está formulado, aborda tres problemas distintos, pero íntimamente articulados: cultura de paz, diálogo interreligioso y diálogo interreligioso como instrumento o mediación para una cultura de paz. Antes de analizar hasta qué punto y en qué sentido el diálogo interreligioso es necesario para una cultura de paz, es importante explicitar qué entendemos por cultura de paz y qué entendemos por diálogo interreligioso. Esta es la estructura fundamental de la reflexión que vamos a desarrollar.

\section{Cultura de paz}

El primer problema con que nos enfrentamos es la comprensión de qué es cultura de paz, qué entendemos por ello y qué queremos decir con ello. No es evidente qué es cultura ni qué es paz, ni, por tanto, qué es cultura de paz. Existe una diversidad de comprensiones de cada una de estas realidades, lo que hace que su estudio sea complejo y problemático en extremo. Por eso es necesario

\footnotetext{
* Traducción de José Andrés Fayos, S.J.

** Doctor en Teología por la Westfälische Wilhelms-Universität de Münster, Alemania, profesor de teología en la Facultad Católica de Fortaleza y presbítero de la diócesis de Limoeiro do Norte.
} 
abordar estas tres cuestiones y dejar claro lo que entendemos por cada una de ellas, o sea, en qué sentido hablamos aquí de cultura, de paz y de cultura de paz.

\subsection{Cultura}

Antes que nada, hay que dejar claro qué entendemos por cultura o a qué nos referimos cuando hablamos de cultura, pues esta es una expresión profundamente equívoca y ambigua. Tiene varios sentidos y suele usarse para indicar realidades muy distintas, aunque no sean necesariamente contrarias.

John B. Thompson, profesor de sociología de la Universidad de Cambridge, por ejemplo, hace notar los "muchos usos, pasados y presentes, del concepto de cultura", y se detiene en cuatro maneras de concebirla ${ }^{1}$.

En primer lugar, lo que denomina el "concepto clásico" de cultura. Lo desarrollaron filósofos e historiadores alemanes en los siglos XVIII y XIX, y se refiere, fundamentalmente, al "proceso de desarrollo intelectual o espiritual" de un pueblo ${ }^{2}$. Por cultura se entiende, aquí, "el proceso en que se desarrollan y ennoblecen las facultades humanas, un proceso facilitado por la asimilación de trabajos académicos y artísticos y ligado al carácter progresista de la época moderna"”.

En segundo lugar, lo que denomina "concepto descriptivo" de cultura; un concepto estrictamente ligado al surgimiento de la disciplina de la antropología, a finales del siglo XIX, interesada en la "descripción etnográfica de sociedades no europeas". Este concepto se refiere al "conjunto de creencias, costumbres, ideas y valores, así como a los artefactos, objetos e instrumentos materiales adquiridos por los individuos en cuanto miembros de un grupo o sociedad". Su estudio abarca "comparación, clasificación y análisis científico de esos diversos fenómenos".

En tercer lugar, lo que define como "concepto simbólico" de cultura, dirigida a los fenómenos simbólicos y a su interpretación. Este concepto se refiere al "conjunto de significados incorporados en las formas simbólicas, que incluye acciones, manifestaciones verbales y objetos significativos de varios tipos, en virtud de los cuales los individuos se comunican entre sí y comparten sus experiencias, conceptos y creencias". El análisis cultural tiene que ver aquí con la "elucidación de ese conjunto de significados, la explicación interpretativa de los significados incorporados a las formas simbólicas".

1. J. B. Thompson, Ideologia e cultura moderna: teoria social crítica na era dos meios de comnicação de massa, Petrópolis, Vozes, 2009, pp. 165 y ss.

2. Ibíd., p. 166.

3. Ibíd., p. 170.

4. Ibíd., p. 171.

5. Ibíd., p. 173.

6. Ibíd., p. 176. 
En cuarto lugar, lo que llama "concepto estructural" de cultura, entendida como "formas simbólicas en contextos estructurados"7. Es la interpretación propuesta y defendida por Thompson. Este concepto pone énfasis tanto en el "carácter simbólico de los fenómenos culturales" como en el hecho de que "tales fenómenos estén siempre insertos en contextos sociales estructurados". Puede ser definido como "el estudio de las formas simbólicas —o sea, acciones, objetos y expresiones significativas de varios tipos - en relación a contextos y procesos históricamente específicos y socialmente estructurados, dentro de los cuales, y por medio de los cuales, se producen, se transmiten y se reciben esas formas simbólicas". El análisis cultural debe, por lo tanto, entenderse aquí, como "el estudio de la constitución significativa y de la contextualización social de las formas simbólicas"9.

Por su parte, Paulo Suess, el teólogo que más se ha confrontado en Brasil con la problemática de la cultura y de la inculturación del Evangelio, identifica siete conceptos de cultura, "usados, a veces, concomitantemente en los mismos textos", de modo particular en "textos teológicos y documentos eclesiásticos"10: (1) cultura como "realizaciones del espíritu humano": arte, literatura, educación, religión; (2) cultura como "superestructura o ideología": reflejo o proyección del mundo material/económico, encubrimiento y justificación del statu quo; (3) cultura como "sector o 'departamento' de la realidad social": política, economía, cultura; (4) cultura como "civilización": progreso material y tecnológico; (5) cultura como "valores universales" o "metacultura": denominador común entre muchos pueblos (paz, amor, solidaridad, trabajo, democracia, etc.); (6) cultura como "antivalores": consumismo, hedonismo, muerte; y (7) cultura como "segundo medioambiente" o "ecosistema humano": diferencia específica de cada grupo (política, estructuras de poder, construcciones materiales, modos de producción, educación, arte, religión, etc. $)^{11}$.

Grosso modo, entre nosotros, en el uso cotidiano de la expresión cultura podemos distinguir tres significados fundamentales que, de alguna manera, articulan y condensan los diferentes sentidos antes indicados.

A veces se usa la expresión cultura para referirse o para designar actividades artísticas (pintura, teatro, poesía, danza, escultura, etc.). Se habla en este contexto de espectáculo cultural, exposición cultural, momento cultural, etc. Aquí se toma cultura como sinónimo de arte en sus más diversas expresiones y, consecuente-

7. Ibíd., pp. 166, 181.

8. Ibíd., p. 181.

9. Ibid., p. 166.

10. P. Suess, "Evangelizar os pobres e os outros a partir de suas culturas: uma proposta de fundo para Santo Domingo", REB 206 (1992), pp. 364-386, aquí p. 366.

11. Cf. ibíd., pp. 366-368. 
mente, como cosa de artista. Se trata, como vemos, de un concepto muy reducido de cultura, tanto en lo que se refiere a su contenido (arte) como en lo que se refiere a los sujetos de ella (artistas). Es el concepto más restringido y elemental de cultura entre nosotros.

Otras veces se habla de cultura como saber, conocimiento, erudición: estudio, lectura, conocimiento de lenguas, de escritores, de artistas, de obras literarias y artísticas, etc. Cuanto más "culta" es una persona, más cultura tiene. En este sentido, cultura aparece como cosa de intelectual, de gente erudita. Se trata de un concepto no solo idealista, sino profundamente elitista de cultura. Además de reducirla al ámbito de la actividad intelectiva (idealismo), ignora su desarrollo y sus expresiones populares, restringiéndola a la actividad de quienes pueden darse el lujo de dedicarse a su cultivo y desarrollo (elitismo).

Por último, la expresión cultura puede usarse para designar la vida concreta de un pueblo. Una manera propia de estructurar y dinamizar la vida. Este concepto se aproxima a lo que Thompson llama "concepto descriptivo" y a lo que Paulo Suess llama "segundo medioambiente" o "ecosistema humano". Se refiere a la vida concreta de un pueblo en su totalidad o a la manera como un determinado pueblo vive su vida. Abarca, ciertamente, la actividad intelectiva de un pueblo (cultura como saber) y, de modo particular, su actividad y sus expresiones artísticas (cultura como arte). Pero abarca también la base material de la actividad intelectual, el modo de producción y distribución de bienes y riqueza, el modo de organización social y política, las diferentes instituciones, las relaciones de poder, la arquitectura, etc. (cultura como modo de vida). Y en este sentido, atañe a todas las personas, al pueblo en su totalidad. No es solo cosa de artistas o intelectuales, sino cosa del pueblo. Este concepto de cultura supera tanto la perspectiva idealista que caracteriza los otros dos modos de concebir la cultura (arte y saber), como la perspectiva elitista que caracteriza el modo anterior (cosa de intelectuales/eruditos). Abarca la vida humana en su totalidad y complejidad y atañe a todas las personas.

Sin pretender hacer un estudio exhaustivo de la problemática de la cultura y de los diversos sentidos en que solemos utilizar esta expresión, no podíamos dejar de esbozar o, al menos, hacer referencia a estos distintos conceptos de cultura. Y no solo por precisión conceptual. Es que, de acuerdo con la comprensión que tengamos de cultura, lo que llamamos cultura de paz tendrá un determinado alcance y se realizará de una determinada manera (arte, saber, modo de vida) y será llevada a cabo por determinados sujetos (artistas, intelectuales/eruditos, pueblo). Se trata, por lo tanto, de una cuestión fundamental y decisiva para nuestro asunto, aunque no podamos ahora desarrollarla suficientemente.

En todo caso, queremos dejar claro que la expresión cultura será tomada aquí en el sentido amplio antes explicitado (modo de vida de un pueblo), tal como aparece en la Constitución Pastoral Gaudium et Spes (53) y lo retoma la 
Exhortación Apostólica Evangelii nuntiandi (20), así como las conferencias episcopales latinoamericanas de Puebla (385-393), Santo Domingo (228) y Aparecida (476). En la formulación de Puebla,

con la palabra "cultura" se indica el modo particular como, en un pueblo, los hombres cultivan su relación con la naturaleza, entre sí mismos y con Dios de modo que puedan llegar a "un nivel verdadera y plenamente humano". Es "el estilo de vida común" que caracteriza a los diversos pueblos; por ello se habla de "pluralidad de culturas". La cultura así entendida, abarca la totalidad de la vida de un pueblo: el conjunto de valores [...] y de antivalores [...], las formas a través de las cuales aquellos valores o antivalores se expresan y configuran, es decir, las costumbres, la lengua, las instituciones y estructuras de convivencia social. (Puebla, 386-387.)

En la formulación más elaborada de Paulo Suess,

la cultura engloba el conjunto de la realidad socio-histórica de un grupo humano. Puesto que la cultura no es un sector o un subsistema de la realidad social, las prácticas políticas, económicas e ideológicas son prácticas al interior del campo cultural [...] La cultura articula visión, percepción, creación y organización social del mundo. La cultura articula el mundo que veo, siento, hago, organizo y sueño. A través de las culturas los grupos humanos definen su identidad frente a la naturaleza y frente a otros grupos humanos. ${ }^{12}$

Este concepto amplio de cultura hace que la problemática de la construcción de una cultura de paz sea algo extremamente complejo; exigirá mucho esfuerzo y mucha creatividad, donde estarán involucrados los más variados sujetos de la vida colectiva, en la medida en que atañe a toda la vida humana y no solo a su dimensión intelectual, y menos aún a su expresión artística.

\subsection{Paz}

También el concepto de paz es muy ambiguo y complejo, y exige, como el concepto de cultura, esclarecimientos y precisiones. No es nada evidente qué sea la paz ni cómo se da su construcción histórica. Se la toma en varios sentidos: ausencia de guerra, bienestar interior, relaciones armoniosas, garantía de derechos, justicia, plenitud de vida, etc. Consideremos, simplemente, dos de estas concepciones de paz que, aunque no se excluyan necesariamente, tienen amplitud diferenciada y acaban desempeñando funciones sociales contrarias.

Hay un concepto de paz que, aunque no sea totalmente falso, es parcial y fácilmente termina en una visión reduccionista de la paz: ausencia de guerra, de violencia física y de derramamiento de sangre. Desde esta perspectiva, una

12. Ibídem. "A disputa pela inculturação", en M. Fabris dos Anjos, Teologia da inculturação e inculturação da teologia, Petrópolis, Vozes, 1995, pp. 113-132, aquí p. 114. 
sociedad, por más injusta que sea, podría ser considerada pacífica, mientras no esté involucrada en guerra y no haya derramamiento de sangre. Este modo de comprender la paz funciona, no raras veces, como legitimación del statu quo de la sociedad: ya sea silenciando o encubriendo las más diversas formas de injusticia y opresión, ya sea responsabilizando a los movimientos populares por los conflictos existentes en la sociedad y tratando o cualificando las luchas por la transformación social como un atentado a la paz.

Esta concepción reduccionista e ideológica de paz es expresamente criticada en varios documentos del magisterio de la Iglesia: "La paz no es ausencia de guerra; ni se reduce a establecer un equilibrio entre fuerzas adversas, ni resulta de una dominación despótica" (GS 78). "La paz no se reduce a una ausencia de guerra, fruto del equilibrio siempre precario de fuerzas" (PP 76). "La paz en América Latina no es, por lo tanto, la simple ausencia de violencia y derramamiento de sangre. La opresión ejercida por los grupos de poder puede dar la impresión de mantener la paz y el orden, pero en realidad no es sino "el germen continuo e inevitable de rebeliones y guerras" (Medellín, Paz 14, 1).

Existe otro concepto más amplio, complejo y verdadero de paz, proveniente de la tradición bíblica y reafirmado en varios documentos del magisterio de la Iglesia. Según este concepto, la paz, ciertamente, tiene que ver con ausencia de guerra, de violencia física y de derramamiento de sangre, pero no se reduce a eso. Se refiere a las condiciones materiales y espirituales de la vida en su totalidad: desde los bienes materiales al ejercicio efectivo de la libertad y la armonía de las relaciones sociales e, incluso, de la relación con Dios. En esta perspectiva, la ausencia de guerra y de violencia física, además de no ser suficiente para cualificar una sociedad como pacífica, puede, como hemos visto, terminar ofuscando otras formas de violencia ${ }^{13}$ que atentan contra la paz, como son la injusticia, la tiranía, el machismo, el racismo, la homofobia, etc.

En la perspectiva bíblica, la paz (shalom) tiene que ver con la ausencia de guerra, con la armonía y el bienestar interior, con el relacionarse las personas entre sí y con Dios, con prosperidad, salud, justicia, felicidad, salvación, en fin, con algo pleno, íntegro, completo ${ }^{14}$. La tradición profética en particular insiste

13. Óscar Romero e Ignacio Ellacuría, en el contexto de guerra civil de El Salvador que costó la vida de más de 75 mil salvadoreños, también la de ellos, se confrontaron con esa problemática e identificaron diversas expresiones de la violencia. $C f$. Ó. A. Romero, "La Iglesia y las organizaciones políticas populares", en Cartas pastorales y discursos de monseñor Óscar A. Romero, Cuadernos Centro Monseñor Romero 18, San Salvador, 2007, pp. 67-105; "Misión de la Iglesia en medio de la crisis del país”, ibíd., pp. 107-168. I. Ellacuría, “Comentarios a la carta pastoral”, en Escritos Políticos, t. II, San Salvador, UCA Editores, 1993, pp. 679-732, aquí pp. 712-732.

14. Cf. X. Léon-Dufour, "Paz", en ídem (dir.), Vocabulário de Teologia Bíblica, Petrópolis, Vozes, 2009, pp. 729-734; H. Gross, "Paz”, en J. B. Bauer, Dicionário de 
mucho en la relación entre paz y justicia: la paz es fruto de la justicia (Is 32, 17). Y la justicia tiene que ver ante todo con el derecho de los pobres ${ }^{15}$ : "Practiquen la justicia y hagan el bien, libren de la mano del opresor al que fue despojado; no maltraten al forastero ni al huérfano ni a la viuda; no les hagan violencia, ni derramen sangre inocente en este lugar" (Jr 22, 3). Bíblicamente hablando, no se pueden separar la paz y la justicia de la suerte de los pobres y oprimidos de este mundo.

Varios textos del magisterio de la Iglesia reafirman y retoman esta perspectiva ( $c f$. GS 78 y PP 76), particularmente en la conferencia de Medellín: “La paz es, ante todo, obra de justicia. Supone y exige la instauración de un orden justo en el que los hombres puedan realizarse como hombres, en donde su dignidad sea respetada, sus legítimas aspiraciones satisfechas, su acceso a la verdad reconocido, su libertad personal garantizada". "La paz solo se obtiene creando un orden nuevo que 'comporta una justicia más perfecta entre los hombres'. En este sentido, el desarrollo integral del hombre, el paso de condiciones menos humanas a condiciones más humanas, es el nombre nuevo de la paz" (Medellín, Paz 14, 1).

En síntesis, la paz tiene que ver con la justicia, con la garantía de las condiciones materiales y espirituales de la vida, la armonía y la serenidad interior, y con la relación con los otros y con Dios. La ausencia de guerra y de violencia física, por más importante y necesaria que sea, es solo un aspecto, no necesariamente el más determinante del shalom o de la paz. Y esto hace mucho más compleja y desafiadora la problemática de la construcción de una cultura de paz.

\subsection{Cultura de paz}

Después de haber explicitado en qué sentido hablamos de cultura (modo de vida) y de paz (shalom), podemos determinar con mayor precisión lo que entendemos por cultura de paz. Esta abarca todos los aspectos y todas las dimensiones de la vida humana y se caracteriza por un modo concreto (paz) de estructurar y dinamizar la vida de un pueblo (cultura); la paz no solo cualifica superficialmente, sino que estructura/dinamiza internamente la cultura. Si la cultura se refiere a la vida concreta de un pueblo en su totalidad, la paz se refiere a la

Teologia Bíblica, São Paulo, Loyola, 1988, pp. 823-827; A. L. Pinheiro de Andrade, "Panorama bíblico sobre a paz como fruto da justiça, Vida Pastoral 265 (2009), pp. 8-13.

15. Cf. J. L. Sicre, Profetismo em Israel: o profeta, os profetas, a mensagem, Petrópolis, Vozes, 2008, pp. 357-380; J. Guillet, "Justiça”, en X. Léon-Dufour, Vocabulário de Teologia Bíblica, óp. cit., pp. 499-510. "Para os semitas, a justiça é não tanto uma atitude passiva de imparcialidade, quanto um empenho do juiz em favor do que tem direito" (ibíd., p. 501). "Nas censuras proféticas, o justo ainda é o que tem direito, mas ele é quase sempre lembrado na sua condição concreta e no seu meio ambiente: esse inocente é um pobre e uma vítima da violência" (ibíd., p. 500). 
realización de esa vida en plenitud y, por consiguiente, a los medios materiales y espirituales de su realización.

Por lo tanto, hablar de cultura de paz es hablar de un modo de organizar y dinamizar la vida, en el cual quedan aseguradas, de modo equitativo, las condiciones materiales y espirituales de la vida humana, tanto individual como colectivamente. Es cierto que una cultura de paz implica ausencia de guerra, de violencia física y de derramamiento de sangre. Pero implica también, insistimos, la garantía de las condiciones materiales y espirituales necesarias para una vida decente: alimento, habitación, salud, descanso, libertad, participación efectiva, respeto, etc.

De esa forma, la garantía y/o negación de esas condiciones materiales y espirituales de la vida humana se convierten en el criterio y la medida de una cultura de paz. Y eso, tanto para constatar su presencia o ausencia en un lugar y tiempo determinados como para orientar su construcción histórica. De uno o de otro modo, esta tiene que pasar por la prueba de fuego: la ausencia o existencia de víctimas. Son estas las que determinan si, y en qué medida, la paz es una realidad o solo un discurso vacío que puede servir, incluso, para encubrir y hasta justificar su real negación.

\section{Diálogo interreligioso}

La expresión diálogo interreligioso suele utilizarse para hablar del diálogo y/o interacción entre las religiones, mientras la expresión ecumenismo se utiliza para designar el diálogo o interacción entre las Iglesias cristianas.

En América Latina se habla muchas veces de macroecumenismo ${ }^{16}$, en lugar de diálogo interreligioso. Algunos se muestran reacios a esta expresión. Primero, porque no enfatiza suficientemente la especificidad del ecumenismo y del diálogo interreligioso y acaba por relativizar el sentido técnico que la expresión ecumenismo ha adquirido en el movimiento ecuménico cristiano: unidad de las Iglesias

16. Cf. '“Manifiesto' del I Encuentro de la Asamblea del Pueblo de Dios (Quito, Ecuador, 1992)", en F. Teixeira (coord.), O diálogo inter-religioso como afirmação da vida, São Paulo, Paulinas, 1997, pp. 147-151; "Proclamación del II Encuentro de la Asamblea del Pueblo de Dios (Cachipay, Colombia, 1996)", ibíd., pp. 153-155; P. Casaldáliga, "O macroecumenismo e a proclamação do Deus da Vida", ibíd., pp. 31-38; P. Casaldáliga y J. M. Vigil, Espiritualidade da Libertação, Petrópolis, Vozes, 1993, pp. 192-200; J. M. Vigil, "Macroecumenismo: teologia latino-americana das religiões", en L. E. Tomita, M. Barros y J. M. Vigil (coords.), Pluralismo e libertação: por uma teologia latino-americana pluralista a partir da fé cristã, São Paulo, Loyola, 2005, pp. 71-88. 
cristianas $^{17}$. Segundo, porque podría sonar como una especie de neocolonialismo cristiano de las religiones, al utilizar, aunque en su sentido etimológico lato, a través del prefijo macro, la misma expresión usada para designar la unidad de las Iglesias cristianas: ecumenismo ${ }^{18}$. En todo caso, la expresión macroecumenismo tiene algunas ventajas que justifican su preferencia y que conviene destacar.

Por un lado, enfatiza, ya en el lenguaje, la necesidad de no separar a los cristianos del conjunto de la humanidad y, por consiguiente, no separar la problemática de la unidad de las Iglesias cristianas (ecumenismo) de la problemática de la unidad de las religiones y de los pueblos (macroecumenismo), por más irreductible que sea. Además, como afirma la Constitución Dogmática Lumen Gentium, la Iglesia debe ser "un germen segurísimo de unidad, de esperanza y de salvación" para todos los pueblos, "sacramento visible de esta unidad salutífera" (LG 9).

Por otro lado, puede poner en guardia, por lo menos desde el punto de vista etimológico, de las trampas del logocentrismo que pone el logos en el centro de todo, como salvación de todo. La problemática de la unidad entre las religiones no es solo una cuestión de logos (discurso, lenguaje) ni se da simplemente por medio de él (diá-logo), como puede sugerir la expresión diálogo interreligioso. El logos, por más importante y decisivo que sea, es solo un modo de intelección ${ }^{19}$. Y la propia intelección solo existe como un momento del proceso más amplio y complejo de la interacción o praxis humana ${ }^{20}$. Solo en el contexto de una praxis determinada se puede comprender el uso/sentido de un logos determinado — carácter práxico del lenguaje ${ }^{21}$ - De modo que el problema de la relación y de

17. Cf. A. Lorscheider, "Diálogo ecumênico e diálogo inter-religioso", Kairós, año II, n. ${ }^{\text {o }}$ 1 (2005), pp. 224-228, aquí p. 224; Pontifício Conselho para a Promoção da Unidade dos Cristãos, "Discurso do cardeal Walter Kasper: 'Paz no mundo inteiro e diálogo entre os cristãos e entre as religiões"'. Disponible en http://www.vatican.va/roman curia/pontifical_councils/chrstuni/documents/rc_pc_chrstuni_doc_20020107_ peace-kasper_po.html. Consultado el 2 de junio de 2011.

18. Esa crítica se hizo en una de las clases de la disciplina de ecumenismo y diálogo religioso que imparto en la Facultad Católica de Fortaleza.

19. Zubiri distingue en el acto intelectivo tres modelos de intelección: aprensión primordial, logos y razón ( $c f . \mathrm{X}$. Zubiri, Inteligencia sentiente. Inteligencia y realidad, Madrid, Alianza Editorial, 2006; ídem, Inteligencia y logos, Madrid, Alianza Editorial, 2002; ídem, Inteligencia y razón, Madrid, Alianza Editorial, 1983).

20. Cf. X. Zubiri, Sobre el hombre, Madrid, Alianza Editorial, 1998, pp. 11-41; ídem, Inteligencia sentiente, óp. cit., pp. 281-285. Para una visión de conjunto del análisis zubiriano de la intelección humana, $c f$. F. de Aquino Júnior, A teologia como intelecção do reinado de Deus: o método da Teologia da Libertação segundo Ignacio Ellacuría, São Paulo, Loyola, 2010, pp. 215-245.

21. Cf. L. Wittgenstein, Philosophische Untersuchungen, Frankfurt am Main, Suhrkamp, 2003, §§ 23, 30, 37, 43. 
la unidad entre las religiones, más que un problema de diá-logo es un problema de inter-acción ${ }^{22}$.

En todo caso, sea que se hable de diálogo interreligioso, sea que se hable de macroecumenismo, es importante (1) no separar el problema de la unidad de los cristianos del problema de la unidad de las religiones y de los pueblos, y (2) darse cuenta de que este problema más que una cuestión de diálogo (discurso, doctrina) es una cuestión de interacción (praxis); que el mismo diálogo no es más que un momento de la interacción religiosa ${ }^{23}$. Esto es fundamental tanto para la comprensión de la problemática de las religiones y de la relación entre ellas (que no se limita al discurso) como para la determinación del modo teórico y práxico de orientar y efectuar la interacción y el diálogo interreligioso.

\section{3. "Diálogo" interreligioso por una cultura de paz}

Después de haber explicitado en los apartados anteriores en qué sentido hablamos de cultura de paz y de "diálogo" interreligioso, nos falta ahora abordar el problema de hasta qué punto y en qué sentido el "diálogo" interreligioso es necesario o al menos puede contribuir a una cultura de paz.

Antes que nada, es necesario tener en cuenta que colocamos y abordamos aquí el "diálogo" interreligioso en una perspectiva muy concreta y determinada, o sea, en vista o en función de una cultura de paz. Por lo tanto, no se trata de

22. En esta perspectiva es muy fecunda y provocadora la propuesta de González Faus de pasar "del diálogo a la diapraxis" ( $c f$. J. I. González Faus, "Religiones de la tierra y universalismo de Cristo. Del diálogo a la diapraxis", en Cristianisme i Justícia (ed.), Universalidad de Cristo, universalidad del pobre. Aportación al diálogo interreligioso, Santander, Sal Terrae, 1995, pp. 103-143.

23. Tratando específicamente de la problemática del ecumenismo, Ellacuría levanta una "sospecha epistemológica" de que "la raíz de la división en la confesión de la fe y, consecuentemente, el camino de la unidad no está fundamentalmente en las diversas formulaciones e interpretaciones de la fe, sino en determinadas praxis personales y estructurales que posteriormente son formuladas en términos de fe" (I. Ellacuría, "El problema 'ecumenismo y promoción de la justicia", en Escritos Teológicos, t. III, San Salvador, UCA Editores, 2002, pp. 375-378, aquí p. 375). Según él, “esta sospecha epistemológica se funda en el hecho de que, en buena parte, las formulaciones y las interpretaciones dependen de la praxis en la que se está inmerso y del interés al que se sirve. Y a su vez, en el hecho de que la praxis se convierte en la verificación real del sentido que se está dando realmente a las formulaciones teóricas" (ibíd., p. 376). En el caso del ecumenismo, eso vale tanto para la comprensión de la división entre las iglesias cristianas como para la búsqueda del camino de la "restauración de la unidad" entre ellas. En el caso del macroecumenismo, vale tanto para la comprensión de la diversidad de tradiciones y, concretamente, de concepciones y doctrinas religiosas, como para la cuestión de la interacción y del diálogo entre esas diversas tradiciones religiosas. 
comparar religiones; menos aún de comparar concepciones o doctrinas religiosas. Ni siquiera se trata de dialogar por dialogar. Se trata, al contrario, de ver hasta qué punto y en qué medida las diferentes religiones (con sus prácticas, sus ritos/símbolos, sus valores, sus concepciones/doctrinas, su potencial humanizador y/u opresor, etc.) y la interacción entre ellas pueden ser, de hecho, fermento de una cultura de paz.

Esto puede parecer a primera vista muy distante e irrelevante, por lo menos para el caso más concreto de América Latina y Brasil, donde el número de quienes declaran pertenecer a tradiciones religiosas no cristianas es muy pequeño. En Latinoamérica el $95 \%$ de la población se declara cristiana y solo el $3.9 \%$ se declara perteneciente a otras tradiciones religiosas (datos de 2010) ${ }^{24}$. En Brasil, $89.5 \%$ de la población se declara cristiana y solo $3.2 \%$ se declara perteneciente a otras tradiciones religiosas (datos de 2000) ${ }^{25}$. Pero este número puede ser relativizado.

En primer lugar, hay que considerar los vínculos no siempre explícitos, por no hablar de la doble pertenencia religiosa, sobre todo con el espiritismo y con las tradiciones de origen africano. En el caso de Brasil, según el censo de 2000, solo 2,262,378 personas se declararon espiritistas y solo 525,011 se declararon relacionadas con religiones afrobrasileñas ${ }^{26}$. Pero el número de quienes frecuentan esporádicamente esos grupos religiosos o incluso de quienes mantienen una doble pertenencia religiosa, y sobre todo el número de quienes sufren su influjo (por ejemplo, reencarnación, "encosto", relación con los muertos, etc.) es, sin ninguna duda, mucho mayor de lo que se puede imaginar.

En segundo lugar, hay que considerar el número de quienes se declaran sin religión, lo que no debe ser identificado - con ligereza - con ateísmo. Según el censo de 2000, este número alcanza el 7.4\% de la población. Que es bastante más del doble de quienes se declaran miembros de otras tradiciones religiosas. Y el número viene creciendo de manera significativa en las últimas décadas: $0.8 \%$ (1970), 1.6\% (1980), $4.7 \%$ (1991), 7.4\% (2000). Forma un grupo cada vez mayor con el cual las religiones tienen que relacionarse y dialogar en nuestra sociedad.

En tercer lugar, hay que considerar el carácter global de la estructuración de nuestra vida colectiva actual, en la que estamos todos vinculados unos a otros, interferimos e influenciamos, más o menos, en la vida unos de los otros. En este contexto no se puede ignorar o tratar como irrelevante el contacto y la influencia,

24. Cf. F. Damen, "Panorama das religiões no mundo 1910-2010", en J. M. Vigil y P. Casaldáliga, Latino-america mundial 2011. Que Deus? Que religião?, São Paulo, Ave Maria, 2011, pp. 22-24, aquí p. 23.

25. Cf. C. Romero Jacob et ál., Atlas da filiação religiosa e indicadores sociais no Brasil, Rio de Janeiro, São Paulo, PUC-Rio, Loyola, 2003, p. 34.

26. Cf. ibíd., p. 103. 
positiva y/o negativa, entre diferentes tradiciones religiosas. Y ello, independientemente de que esas tradiciones se encuentren en el mismo espacio geográfico. Tal contacto e influencia es un factor cargado de consecuencias simbólicas y práxicas en el mundo actual. Basta ver las referencias constantes en los movimientos eco-sociales a tradiciones religiosas indígenas, africanas y orientales.

En cuarto lugar, hay que considerar el carácter teologal de las diversas tradiciones religiosas e incluso de las diversas culturas y de la praxis humana en general. Ya la declaración Nostra Aetate, del Concilio Vaticano II, sobre la relación de la Iglesia católica con las religiones no cristianas, reconoce explícitamente que estas "reflejan un destello de aquella Verdad que ilumina a todos los hombres", afirma que "la Iglesia católica no rechaza nada de lo que en estas religiones hay de santo y verdadero" y exhorta a los católicos a que "reconozcan, guarden y promuevan aquellos bienes espirituales y morales, así como los valores socio-culturales que en ellos existen" (NA 2). Rechazarlas o negarlas sin más es rechazar y negar el Espíritu de Dios que actúa en ellas.

Todo esto muestra que la problemática del "diálogo" interreligioso adquiere una importancia cada vez mayor en nuestra sociedad, llegando a ser una necesidad y una urgencia social (configuración plural de la vida colectiva) y un imperativo religioso (potencial salvífico-humanizador de las diversas tradiciones religiosas).

El problema es cómo hacer para se torne real y efectivo, de modo que contribuya a la construcción de una cultura de paz, o sea, cómo las religiones y la interacción entre ellas pueden ser fermento y mediación de una cultura de paz. En este sentido, hay que recordar el criterio y la medida de una cultura de paz antes indicados: los pobres, los oprimidos, los excluidos y los débiles. Ellos constituyen, si no $\mathrm{el}$ criterio y la medida de autenticidad de todas las tradiciones religiosas, como es el caso de la tradición judeo-cristiana, por lo menos una de sus características o marcas fundamentales y, por consiguiente, deben constituir también el criterio y la medida de la interacción del diálogo entre ellas. Las religiones, por lo general, son particularmente sensibles a las situaciones de sufrimiento e injusticia, al clamor de los pobres y oprimidos, y tienen como una de sus tareas más importantes el cuidado y la defensa de los pobres, oprimidos y débiles - aunque no siempre actúen de modo consecuente e incluso contribuyan, por omisión o complicidad, al mantenimiento de situaciones de pobreza, injusticia, opresión y exclusión- No es casual que desempeñen un papel y una función importantes en lo que respecta a los valores y al modo de estructurar y reglamentar la vida individual y colectiva.

Por aquí podemos encontrar un camino fecundo para volver efectivas y eficaces las potencialidades de las religiones y de la interacción entre ellas para la construcción de una cultura de paz. Se trata de algo que tiene que ver con la propia identidad de las diversas tradiciones religiosas (su potencial salvífico- 
humanizador) y que constituye, como hemos visto, la propia medida y el criterio de una cultura de paz (su prueba de fuego). En el cuidado y en la defensa de la vida de los pobres, oprimidos y débiles, y en la denuncia y enfrentamiento con todo lo que amenaza y destruye sus vidas es donde las religiones y la interacción entre ellas se convierten en camino y mediación para una cultura de paz, al tiempo que realizan su identidad más profunda y radical. En la perspectiva de una cultura de paz y a partir de la identidad más profunda y radical de las diversas tradiciones religiosas, el macroecumenismo o el "diálogo" interreligioso está, por lo tanto, intrínsecamente vinculado a la vida y a la suerte de los pobres, oprimidos y débiles de este mundo. Pedro Casaldáliga lo formula muy bien. Es un texto largo, pero vale la pena citarlo.

Macro-ecumenismo es dialogar inter-religiosamente, pero siempre en un compromiso social por los excluidos. Yo no entendería de manera alguna un diálogo inter-religioso si no lo entendiese como compromiso socio-político y económico, al servicio de las mayorías excluidas que es la mayor parte de la familia de ese Dios de la vida que uno quiere proclamar. Hacer de la fe en el Dios de la Vida un culto militante a la vida, por amor a la obra y al sueño de ese Dios. Y dialogar con todas las religiones y no solo con las llamadas "grandes", pues en este caso nos estaríamos alejando de la tradición evangélica, ya que el Evangelio se distingue por dialogar con lo que es pequeño. Dialogar también con las pequeñas religiones, con las religiones indígenas, con la religión Tapirapé. ${ }^{27}$

Me parece elemental y fundamental destacar, siempre, en el diálogo interreligioso el contenido y el objetivo de este diálogo. No se trata de colocar las religiones en una reunión para que discutan pacíficamente sobre religión, alrededor de sí mismas narcisísticamente. El verdadero diálogo inter-religioso debe tener como contenido y como objetivo la causa de Dios que es la propia humanidad y el universo. En la humanidad la causa prioritaria es la gran masa empobrecida y excluida; y en el universo, la tierra, el agua y el aire profanados.

Y refiriéndose a la tesis de Hans Küng de que "no habrá paz entre las naciones si no hay paz entre las religiones, y que no habrá paz entre las religiones si no hay diálogo entre ellas", afirma sin medias tintas: "Es necesario añadir que este diálogo será inútil, hipócrita y hasta blasfemo, si no está dirigido a la Vida y a los pobres, sobre los derechos humanos, que son también divinos"28.

No se trata aquí de salirse por la tangente, desviándose de una cuestión explícitamente "religiosa" hacia cuestiones sociales. Y si no fuera posible el diálogo

27. P. Casaldáliga, "O macroecumenismo e a proclamação do Deus da Vida", óp. cit., p. 36. 28. P. Casaldáliga, "Prólogo", en L. Tomita, M. Barros y J. M. Vigil, Pelos muitos caminhos de Deus: desafios do pluralismo religioso à Teologia da Libertação, Goiás, Rede, 2003, pp. 5-8, aquí p. 7. 
sobre cuestiones propiamente "religiosas", por lo menos podríamos trabajar juntos por la vida, por la justicia y por la paz.

Esto es así, en primer lugar, porque, como afirman los obispos de América Latina en la introducción a las conclusiones de Medellín, retomando el discurso de Pablo VI en la clausura del Concilio Vaticano II, cuando "la Iglesia latinoamericana centró su atención en el hombre de este continente (...) no se ha 'desviado' sino que se ha 'vuelto' hacia el hombre, consciente de que 'para conocer a Dios es necesario conocer al hombre". Cuidar de la vida, particularmente de la vida humana amenazada, herida, víctima de injusticia no es, pues, algo externo ni secundario, sino algo que toca el núcleo más íntimo de las propias tradiciones religiosas, en lo que tienen de salvífico-humanizador.

En segundo lugar, porque lo que se podría llamar un discurso más propiamente religioso (conceptos o doctrinas religiosas) no es independiente de la praxis del grupo que formula y profesa tal discurso. El lenguaje, en general, y las teorías/doctrinas, en particular, están profundamente ligadas a una dinámica o a un modo concreto de vida, dentro del cual surgen, se desarrollan y elaboran, y al que se remiten de alguna manera. Así, por ejemplo, la imagen de Dios de Jesús es inseparable de su vida concreta. El Dios en quien Jesús cree, a quien entrega su vida, se manifiesta en la manera como él vive: al actuar con bondad y misericordia para con los caídos al margen del camino, revela un Dios bondadoso y misericordioso; cuando acoge personas consideradas impuras y pecadoras, revela a un Dios que es perdón y gratuidad; cuando socorre a las personas en sus necesidades y cuando defiende el derecho de los pequeños y oprimidos, revela a un Dios que es justicia; cuando hace suyas las necesidades de la humanidad sufriente, revela a un Dios parcial y partidario de los pobres y oprimidos de este mundo. Pensar y efectuar, pues, la interacción y el diálogo entre las religiones a partir de los pobres, oprimidos y débiles, además de no ser un "desvío" de la cuestión propiamente religiosa, ayuda a reformularla de manera más coherente con su potencial salvífico-humanizador y a volver más efectiva y fecunda su tarea y su contribución a la construcción de una cultura de paz. Es el problema de la correcta y consecuente articulación ortopraxis-ortodoxia.

En el cuidado y en la defensa de la vida de los pobres, oprimidos y débiles, las religiones y la interacción/diálogo entre ellas contribuyen a una cultura de paz, al mismo tiempo que hacen real y efectivo su potencial y su misión salvífico-humanizadora, y pueden reelaborar su discurso/doctrina de manera cada vez más coherente con esa potencialidad y misión salvífico-humanizadora.

\section{A modo de conclusión}

Por lo dicho, la mayor contribución de las religiones y de la interacción/ diálogo entre ellas a la construcción de una cultura de paz tiene que ver con su 
particular sensibilidad hacia las situaciones de pobreza, injusticia y sufrimiento, y con su cuidado y acción en favor/defensa de los pobres, oprimidos y débiles — aquello que, en la Iglesia latinoamericana, llegó a formularse como "opción por los pobres"- Y Y eso, tanto por tratarse de algo que tiene que ver con la identidad práxico-teórica más profunda y radical de las diversas tradiciones religiosas (su potencial salvífico-humanizador), como por tratarse de aquello que constituye la propia medida y criterio de una cultura de paz (su prueba de fuego).

La gran cuestión es cómo lograr que eso se haga real y efectivo en el contexto y en las situaciones que nos toca vivir. Es el problema de las mediaciones teóricas y práxicas que exige la opción por los pobres, si no queremos reducirla a un discurso vacío e ineficaz. Pero eso va más allá de los límites y la pretensión de este trabajo. 